\title{
A randomized trial of a pain management intervention for adults receiving substance use disorder treatment
}

\author{
Mark A. Ilgen 1,2, Amy S. B. Bohnert ${ }^{1,2}$, Stephen Chermack ${ }^{1,2}$, Carly Conran ${ }^{3}$, Mary Jannausch ${ }^{1,2}$, \\ Jodie Trafton $^{4,5}$ \& Frederic C. Blow ${ }^{1,2}$ \\ VA Center for Clinical Management Research (CCMR), Veterans Health Administration, Ann Arbor, MI, USA,' Department of Psychiatry, University of Michigan, Ann \\ Arbor, MI, USA, ${ }^{2}$ School of Literature, Science and Arts, University of Michigan, Ann Arbor, MI, USA, ${ }^{3}$ VA Program Evaluation and Resource Center (PERC), Veterans \\ Health Administration, Menlo Park, CA, USA ${ }^{4}$ and Department of Psychiatry and Behavioral Sciences, Stanford University, Palo Alto, CA, USA ${ }^{5}$
}

\begin{abstract}
Background and Aims Chronic pain is difficult to treat in individuals with substance use disorders and, when not resolved, can have a negative impact on substance use disorder treatment outcomes. This study tested the efficacy of a psychosocial pain management intervention, ImPAT (improving pain during addiction treatment), that combines pain management with content related to managing pain without substance use. Design Single-site, parallel-groups randomized controlled trial comparing ImPAT to a supportive psychoeducational control (SPC) condition; follow-up assessments occurred at 3, 6 and 12 months. Setting The Ann Arbor VA Substance Use Disorder treatment program, USA. Participants Veterans Health Administration patients $\{n=129$; mean [standard deviation (SD)], age = 51.7 (9.5); 115 of $129(89 \%)$ male; ImPAT $(n=65)$; SPC $(n=64)\}$. Intervention ImPAT combines principles of cognitivebehavioral therapy and acceptance-based approaches to pain management with content related to avoiding the use of substances as a coping mechanism for pain. The SPC used a psychoeducational attention control treatment for alcoholism modified to cover other substances in addition to alcohol. Measurements Primary: Pain intensity over 12 months; secondary: pain-related functioning, frequency of alcohol and drug use over 12 months. Findings Primary: randomization to the ImPAT intervention versus SPC predicted significantly lower pain intensity $\{\beta$ [standard error $(\mathrm{SE})]=-0.71(0.29) ; 95 \%$ confidence interval $(\mathrm{CI})=-1.29,-0.12\}$; secondary: relative to the SPC condition, those who received ImPAT also reported improved pain-related functioning $[\beta(\mathrm{SE})=0.27(0.11) ; 95 \% \mathrm{CI}=0.05,0.49]$ and lower frequency of alcohol consumption $[\beta(\mathrm{SE})=-0.77 ; 95 \% \mathrm{CI}=-1.34,-0.20]$. No differences were found between conditions on frequency of drug use over follow-up. Conclusions For adults with pain who are enrolled in addictions treatment, receipt of a psychological pain management intervention (improving pain during addiction treatment) reduced pain and alcohol use and improves pain-related functioning over 12 months relative to a matched-attention control condition.
\end{abstract}

Keywords Cognitive-behavioral, pain, substance use disorder.

Correspondence to: Mark Ilgen, Department of Psychiatry, University of Michigan, 2800 Plymouth Road, Ann Arbor MI 48109, USA. E-mail: marki@med.umich.edu Submitted 10 May 2015; initial review completed 22 July 2015; final version accepted 10 February 2016

\section{INTRODUCTION}

Chronic pain is commonly reported in the general population, and is often associated with a lower quality of life and psychiatric comorbidities, including substance use disorders (SUDs) [1-3]. The rate of co-occurrence of chronic pain and SUDs is higher in clinical settings than in the general population [4], and is particularly prevalent in patients in SUD treatment programs [5-8]. Chronic pain often persists following SUD treatment, and pain is associated with poorer substance-related outcomes in individuals treated for SUDs [9]. Providing adequate pain relief for those with SUDs is also challenging, given the high abuse potential of prescription opioids, a common treatment for chronic pain [10].

Previous studies have found consistently that nonpharmacological pain management, such as cognitivebehavioral therapy (CBT) and acceptance-based approaches, can reduce self-reported pain and improve functioning [11-14]. However, most prior randomized trials have excluded individuals with past or active SUDs, and none have described the impact of these approaches 
on substance use or specifically among individuals with substance use disorders. An open trial of CBT described positive pain- and substance-related outcomes in 44 individuals with both pain and SUDs over the course of 12 months [15]. A recent study of 349 opioiddependent adults found that patients were receptive to a CBT pain management approach delivered concurrently with methadone maintenance treatment [16]. In a small pilot study, we previously found general reductions in pain and substance use following receipt of a CBT and acceptance-based pain management intervention in addition to SUD treatment [17]. However, this prior work lacked a control group, so it was not possible to attribute improvements to the intervention versus other changes that might occur with standard SUD treatment.

The present study was designed to test the efficacy of a psychosocial pain management intervention, referred to as ImPAT (improving pain during addiction treatment), that combines principles of CBT and acceptance-based approaches to pain management with content related to avoiding the use of substances as a coping mechanism for pain. Specifically, we compared randomization to ImPAT or a supportive psychoeducational control (SPC) condition to examine during the 12-month follow-up: (i) whether participants who receive ImPAT reported lower pain intensity than those in SPC; and (ii) as secondary outcomes, if those who received ImPAT reported better pain-related functioning and fewer days of alcohol and drug use than those who received SPC.

\section{METHODS}

Patients seeking care from the out-patient or intensive out-patient SUD treatment programs at the Ann Arbor VA Medical Center were recruited to participate in this study; approximate dates of recruitment were October 2010-January 2013. After providing informed consent, 193 individuals were screened. Eligible participants (see criteria below) completed a second consent process for the trial phase of the project and were randomized to condition. Neither the study staff nor participants were blind to conditions. Because both ImPAT and SPC were provided in group format, there was often a delay between completion of the baseline assessments and the start of the ImPAT or SPC groups in order to recruit sufficiently large groups (range $=1-92$ days, median $=23$ days $)$. All groups met weekly for 10 weeks. Participants were re-assessed at 3, 6 and 12 months after the start of their group sessions. This study was approved by the institutional review board at the Ann Arbor VA and the study protocol binder and data are stored at the Ann Arbor VA (ClinicalTrials.gov registration \#NCT00982410).
Inclusion criteria were: average pain intensity $>4$ during the past 3 months [18], current receipt of SUD services, aged 18 years or greater, ability to speak and understand English and capacity to give informed consent. Exclusion criteria were: a Mini-Mental State Examination (MMSE [19]) score less than 21, psychiatric hospitalization within the past month, endorsement of current psychotic symptoms on the Brief Symptom Inventory (BSI [20]) combined with noticeable bizarre thoughts or behavior during the interview or inability to give informed, voluntary, written consent.

\section{Sample size and randomization}

Sample size was based on $80 \%$ power, a between-group difference in time-averaged change from baseline of 1.5 on a 0-10 scale [standard deviation ( $\mathrm{SD}=2.7, \alpha=0.01$ ], to detect treatment differences in pain intensity. Based on these assumptions, the trial was designed to recruit approximately 128 individuals. Because both conditions were delivered in groups, the sample size exceeded 128 so that the final pair of groups was similar in size to prior groups. Randomization to one of two conditions (ImPAT or SPC conditions) as parallel groups with a $1: 1$ ratio was conducted, blocking on gender, via an adaptive randomization biased-coin-design method by the center biostatistician, Myra Kim.

\section{Outcome measures}

Assessments were conducted in person by research staff at the Ann Arbor VA Medical Center. Participants were asked to complete a urine drug screen as part of all baseline and follow-up assessments.

\section{Primary outcome}

1 Pain intensity was assessed via the Numeric Rating Scale (NRS), utilizing an 11-point scale $(0=$ no pain, $10=$ worst pain imaginable) to measure average pain over the past 7 days [18].

\section{Secondary outcomes}

1 Pain-related functioning was measured with the 18item General Activity scale of the West Haven-Yale Multidimensional Pain Inventory $(\alpha=0.822)$ [21].

2 Pain tolerance was measured using the cold-pressor task [22]. The procedure [23] involved immersion of the non-dominant hand and arm in an ice chest filled with water that was maintained at a temperature of $33 \pm 1$ Fahrenheit. The water was circulated with a pump to prevent local warming of the water around the hand and arm. Each participant was asked to immerse the hand and forearm, and to keep the hand still with palm down. Participants were instructed to hold their hand in the water for as long as they could, 
but that could remove their hand at any point they to terminate the task. To ensure safety, the task's maximum allowable duration was set at 2 minutes.

3 Days of alcohol use in the past 30 days was measured using the time-line follow-back (TLFB) interview. The TLFB is a calendar-assisted, interviewer-administered, structured interview with strong test-retest reliability [24,25]. Participants are asked to recall each day that they drank during the past 30 days.

4 Days of drug use in the past 30 days was measured similarly using the TLFB interview and represents the frequency of any drug use in the past 30 days summing across all types of drugs (including non-medical use of prescription drugs) with a range of 0-30. Even if more than one drug was used within a single day, this day was still given a value of 1 .

\section{Intervention and control conditions}

The ImPAT and SPC conditions were designed to be identical in terms of the amount of therapist/patient contact. Both conditions involved 10 1-hour sessions that were delivered over the course of approximately 10 weeks and delivered by a masters-level therapist.

The ImPAT intervention [17] was focused on how a psychosocial model of pain was associated with functioning and relapse prevention. Substance use was conceptualized primarily as a maladaptive coping response to pain and the treatment addressed substance use by encouraging the use of more appropriate coping skills and improving self-efficacy to manage pain without substance use. The concepts of acceptance of, and adaptation to, chronic pain were highlighted in all sessions. Additionally, two sessions were focused primarily on developing greater acceptance of pain. All sessions highlighted the importance of tolerating depression and anxiety, and one session focused specifically on addressing depression. The portion of treatment that focused on cognitions included sessions on thought monitoring, cognitive reconceptualization and cognitive restructuring. The behaviorally oriented content included sessions on behavioral activation and attention diversion as well as a general focus on pacing [26], or strategically planning to avoid over-activity, as well as guided muscle relaxation.

The SPC condition was designed to match the ImPAT condition in terms of level of attention and the non-specific aspects of receiving support for pain and substance misuse. Specific content related to pain for the SPC group was similar to that which was used in a prior study of pain [27], modified to cover multiple pain conditions. Content related to substance use was based on a psychoeducational attention control treatment for alcoholism [28], modified to cover other substances in addition to alcohol. SPC sessions helped patients to understand more clearly the origins and consequences of pain and substance use in their life. However, topics related to psychological factors associated with pain, possible psychosocial coping mechanisms and acceptance of and adaptation to pain were not part of the content of the group.

\section{Statistical analysis}

Prior to analysis, all continuous and categorical measures were evaluated for their distributional characteristics. Cross-sectional analyses of participant characteristics were undertaken via analysis of variance for continuous measures, and $\chi^{2}$ tests or Fisher's exact test for frequencies, as appropriate.

Repeated-measures mixed models were utilized to assess the average of the primary outcome, as well as the secondary measure of pain-related functioning across the follow-up, with adjustment for baseline level of the same outcome. Zero-inflated negative-binomial modeling was used for the secondary outcomes of alcohol and drug use to address very high frequencies of zeroes in substanceuse distributions in the follow-up period. All modeling approaches had baseline measure as a random effect; subject effects were nested within therapy group assignment because subjects within the same therapy group were not necessarily independent of each other due to the common therapy environment. Therapy group was utilized to block subjects for the alcohol and drug models. Treatment group was treated as a fixed effect in all models and the impact of this variable was examined as the indicator of the impact of random assignment to ImPAT versus SPC. Time $\times$ treatment interaction effects were evaluated during the model building phase, and dropped because they did not contribute to model fit. All findings are reported on the outcome's original scale.

\section{Missing data}

The analytical approach utilized all available data for each outcome (i.e. if follow-up data were available at only two of the three follow-up assessments, values for these two assessments would be used in model estimation). Followup data were included, whenever available, for every participant who was randomized and did not withdraw from the study, irrespective of level of participation in the intervention conditions.

\section{RESULTS}

\section{Sample recruitment and retention}

A total of 193 participants consented and completed the initial screening assessment (Fig. 1); 145 (75.1\%) were eligible and consented to the baseline assessment (15.6\% ineligible, $3.6 \%$ were eligible but withdrew prior to 


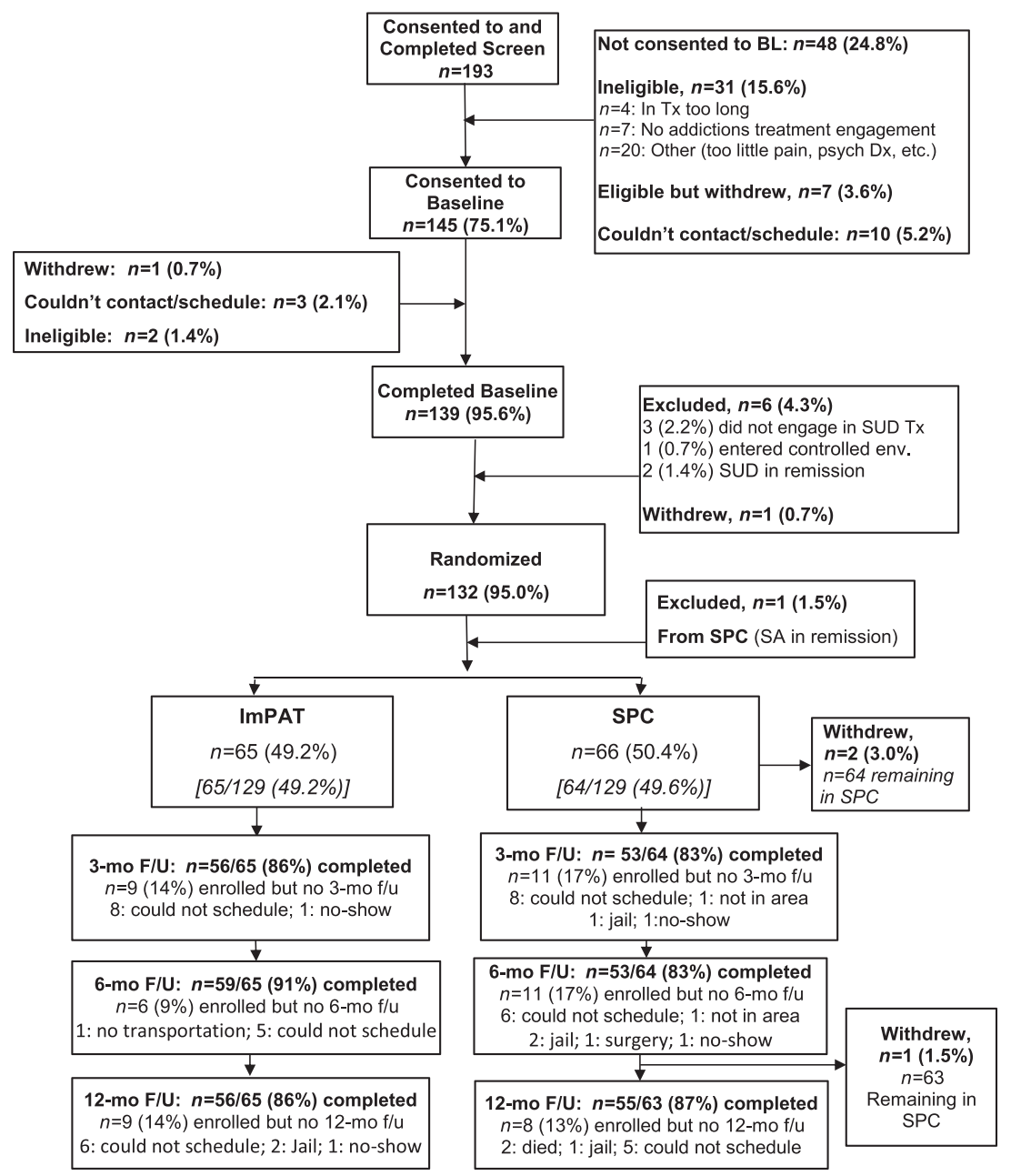

Figure I Randomized trial of ImPAT (improving pain during addiction treatment) versus SPC (supportive psychoeducational control): recruitment

consenting and $5.2 \%$ did not provide consent for logistical reasons). Of those who consented, 139 (95.6\%) completed the baseline (one withdrew, three did not complete all assessments and two were found to be ineligible during the assessment). Of the 139 participants who completed the baseline, $132(95.0 \%)$ were randomized initially to either the ImPAT or PSC conditions (six were found to be ineligible from baseline responses and one withdrew). One additional participant was excluded due to having a substance use disorder in remission prior to attending any treatment sessions. Of the remaining 131 individuals who were randomized ( $n=65$ for ImPAT; $n=66$ for SPC), two participants in the SPC group withdrew consent before attending any therapy sessions, leaving 129 individuals $(n=65$ for ImPAT; $n=64$ for SPC).

Participants were predominantly male $(89 \%)$, white (59\%) and had an average age of $51.7(\mathrm{SD}=9.5)$ years, similar to the characteristics of VHA patients overall. Table 1 includes more details about the sample. No baseline differences were found between conditions with the exception of employment ( $97 \%$ unemployed in ImPat versus $88 \%$ in SPC).
Of 129 participants, $123(95 \%)$ provided data at one or more of the follow-ups. The specific follow-up rates at each time-point were $84 \%$ (ImPAT $=86 \%$; $\mathrm{SPC}=83 \%)$ at 3 months, $87 \%($ ImPAT $=91 \%$; $\mathrm{SPC}=83 \%)$ at 6 months and $87 \%($ ImPAT $=86 \%$; $\mathrm{SPC}=87 \%)$ at 12 months. One participant withdrew prior to the 12-month follow-up and is not included in the denominator for the 12-month rate. No differences in follow-up rates were found between the ImPAT and SPC conditions.

\section{Therapy attendance}

Of the 129 enrollees, $n=102(79 \%)$ attended one or more therapy sessions; 55 of $65(85 \%)$ in ImPAT group and 47 of $64(73 \%)$ in SPC. The rate of treatment attendance was not significantly different between conditions. The mean number of days between baseline assessment and initiation of treatment did not differ significantly between groups: $28.9(\mathrm{SD}=21.6)$ in ImPAT and 30.4 $(\mathrm{SD}=21.1)$ in SPC. 
Table 1 Demographic characteristics, baseline pain intensity and baseline pain tolerance, according to randomized treatment group.

\begin{tabular}{|c|c|c|c|}
\hline & \multirow[b]{2}{*}{ Total } & \multicolumn{2}{|c|}{ Treatment Group } \\
\hline & & SPC & $\operatorname{ImPAT}$ \\
\hline$n$ & 129 & 64 & 65 \\
\hline $\begin{array}{l}\text { Age (mean, standard } \\
\text { deviation) }\end{array}$ & $51.7(9.5) 5$ & $51.7(9.8)$ & $51.7(9.2)$ \\
\hline \multicolumn{4}{|l|}{ Gender $(n, \%)$} \\
\hline Men & $115(89 \%)$ & $57(89 \%)$ & $58(89 \%)$ \\
\hline Women & $14(11 \%)$ & $7(11 \%)$ & $7(11 \%)$ \\
\hline \multicolumn{4}{|l|}{ Race/ethnic group ( $n, \%)$} \\
\hline White & $76(59 \%)$ & $41(64 \%)$ & $35(54 \%)$ \\
\hline All others & $53(41 \%)$ & $23(36 \%)$ & $30(46 \%)$ \\
\hline \multicolumn{4}{|l|}{ Partnered $(n, \%)$} \\
\hline Yes & $26(20 \%)$ & $15(24 \%)$ & $11(17 \%)$ \\
\hline No & $102(80 \%)$ & $48(76 \%)$ & $54(83 \%)$ \\
\hline \multicolumn{4}{|l|}{ Employed (n, \%) } \\
\hline Yes & $10(8 \%)$ & $2(3 \%)$ & $8(12 \%)$ \\
\hline No & $119(92 \%)$ & $62(97 \%)$ & $57(88 \%)$ \\
\hline \multicolumn{4}{|l|}{ Education $(n, \%)$} \\
\hline High school or less & $58(45 \%)$ & $31(48 \%)$ & $27(42 \%)$ \\
\hline Post-high school & $72(55 \%)$ & $33(52 \%)$ & $38(58 \%)$ \\
\hline \multicolumn{4}{|c|}{$\begin{array}{l}\text { TLFB: 30-day substance use }{ }^{\mathrm{b} . \mathrm{c}} \\
\text { (mean, standard deviation) }\end{array}$} \\
\hline Days alcohol use & $5.2(9.1)$ & $4.7(8.6)$ & $5.7(9.7)$ \\
\hline Days marijuana use & $3.2(7.8)$ & $3.4(8.5)$ & $2.9(7.2)$ \\
\hline Days cocaine use & $0.4(1.9)$ & $0.4(1.8)$ & $0.5(2.0)$ \\
\hline Days heroin use & $0.5(2.8)$ & $0.6(2.8)$ & $0.5(2.7)$ \\
\hline Days Rx opioid misuse & $0.02(0.2)$ & $0.0(0.0)$ & $0.03(0.2)$ \\
\hline Days Rx opioid use (licit) & $5.7(10.7)$ & $6.2(11.1)$ & $5.1(10.3)$ \\
\hline
\end{tabular}

'aisher's exact tests were utilized to compare conditions. All differences were non-significant, with the exception of employment $(P<0.05) .{ }^{{ }^{b}} \%$ endorsing any use in past 30 days for: alcohol, $43 \%$; marijuana, $27 \%$; cocaine, $8 \%$; heroin, $6 \%$; Rx opioid misuse, $0.8 \%$; Rx opioid licit use, $32 \%$. ${ }^{c}$ Wilcoxon's signedrank test was used to compare conditions on days of use of different substances; all differences were non-significant; days of $\mathrm{Rx}$ opioid misuse not tested, due to extremely low numbers of people endorsing. TLFB $=$ timeline follow-back; ImPAT = improving pain during addiction treatment; SPC $=$ supportive psychoeducational control.

\section{Primary outcome}

Pain intensity. Table 2 and Fig. 2 report results of longitudinal modeling of outcome measures. The ImPAT condition was associated with significantly lower pain intensity ratings across the three time-periods than the SPC condition. Specifically, the average pain intensity rating across follow-ups was 5.8 compared to 7.1 at baseline for the ImPAT condition, and 6.47 compared to 7.2 at baseline for the SPC condition.

\section{Secondary outcomes}

Pain-related functioning was significantly greater in ImPAT relative to the SPC condition.

Pain tolerance. The study intended to evaluate pain tolerance. Analysis of this outcome was limited by increasing rates of refusal for the pain tolerance task during followup (from $3.7 \%$ at baseline to $23 \%$ at 12 months follow-up) and substantial ceiling and floor effects in the measure. None the less, analyses using a beta regression approach to account for the distribution of responses were conducted; we did not find significant differences between conditions.

Alcohol use. Participants in the ImPAT condition reported fewer days of alcohol use during the follow-up period than participants in the SPC condition (Table 2). This effect was seen in the number of days of alcohol use but not in the difference between any versus no use (i.e. in the inflate statement; model not shown). As shown in Fig. 2, drinking was relatively similar between conditions at the 3-month follow-up but differences between conditions emerged at the 6- and 12-month follow-ups. Despite the suggestion of an increasing effect of the intervention on alcohol use over time, an interaction term of follow-up period and group was not significant.

Drug use. No difference was seen between conditions in the measure of days of drug use. The change from baseline was not statistically significant between the two conditions (Table 2). Additional models with treatment as an indicator variable in the inflate statement indicated that treatment group was also not associated with the likelihood of using drugs versus not using.

\section{DISCUSSION}

The present results indicate that a psychotherapeutic approach that combines CBT and acceptance-based principles produced greater improvements in self-reported pain and functioning during a 12-month follow-up period than a psychoeducational control group in patients currently receiving treatment for SUDs. This intervention produced significantly greater reductions in alcohol use over 12 months compared to the control condition. No differences were found between conditions on measures of drug use, although the combination of a relatively small sample size and the considerable variability in the type and extent of drug use at baseline probably made detection of potential differences difficult. Overall, the present results indicate that a CBT and acceptance-based intervention (referred to as ImPAT) can improve outcomes in adults with SUDs as a supplement to standard outpatient SUD treatment.

CBT and acceptance-based approaches to pain management have a solid evidence base; however, existing trials of these interventions have typically excluded those with SUDs and/or have not examined SUD-related outcomes. Recently, a few pilot studies have highlighted the potential viability of psychosocial pain management approaches for individuals being treated for SUDs [16]. The present 
Table 2 Pain measures and substance use over the 1-year follow-up period, adjusted for baseline pain, functioning or substance use, with therapy group effect taken into account.

\begin{tabular}{|c|c|c|c|c|}
\hline \multicolumn{5}{|c|}{ Pain intensity and functioning } \\
\hline \multicolumn{2}{|c|}{ Primary outcome: pain intensity (NRS-1) $)^{b, c, d}$} & \multicolumn{2}{|c|}{ Treatment group } & \multirow{2}{*}{$\begin{array}{l}\text { AIC } \\
1193.6\end{array}$} \\
\hline & $\beta(\mathrm{SE})$ & SPC & ImPAT & \\
\hline Pain intensity at baseline & $0.44(0.09)^{*}$ & $\begin{array}{l}\text { LSMean } \\
(\mathrm{SE})\end{array}$ & $\begin{array}{l}\text { LSMean } \\
(\mathrm{SE})\end{array}$ & \\
\hline ImPAT & $-0.71(0.29)^{*}$ & \multirow{2}{*}{$6.45(0.18)$} & \multirow[t]{2}{*}{$5.74(0.24)^{*}$} & $\begin{array}{l}\text { Effect } \\
\text { size }\end{array}$ \\
\hline SPC & (referent) & & & 0.453 \\
\hline \multicolumn{2}{|l|}{$95 \% \mathrm{CI}, \beta$ (treatment) } & \multicolumn{2}{|l|}{$-1.29,-0.12$} & \\
\hline \multicolumn{2}{|c|}{$\begin{array}{l}\text { Secondary outcome: general activity (WHY } \\
\text { MPI) }\end{array}$} & & & AIC \\
\hline & $\beta(\mathrm{SE})$ & SPC & ImPAT & 724.2 \\
\hline $\begin{array}{l}\text { General activity at } \\
\text { baseline }\end{array}$ & $0.56(0.07)^{*}$ & $\begin{array}{l}\text { LSMean } \\
(\mathrm{SE})\end{array}$ & $\begin{array}{l}\text { LSMean } \\
(\mathrm{SE})\end{array}$ & \\
\hline ImPAT & $0.27(0.11)^{*}$ & \multirow{2}{*}{$1.96(0.07)$} & \multirow[t]{2}{*}{$2.23(0.08)^{*}$} & $\begin{array}{l}\text { Effect } \\
\text { size }\end{array}$ \\
\hline SPC & (referent) & & & 0.358 \\
\hline \multicolumn{2}{|l|}{$95 \% \mathrm{CI}, \beta$ (treatment) } & \multicolumn{2}{|l|}{$0.05,0.49$} & \\
\hline \multicolumn{5}{|c|}{ Substance use, from time-line follow-back } \\
\hline \multicolumn{2}{|c|}{$\begin{array}{l}\text { Secondary outcome: frequency of alcohol } \\
\text { use (f/u) }\end{array}$} & \multicolumn{2}{|l|}{$\beta(\mathrm{SE})$} & AIC \\
\hline \multicolumn{2}{|c|}{ Days used alcohol at baseline } & \multicolumn{2}{|l|}{$0.08(0.01)^{*}$} & 1162.5 \\
\hline \multicolumn{2}{|c|}{ ImPAT } & \multicolumn{2}{|l|}{$-0.77(0.29)^{*}$} & \\
\hline \multicolumn{2}{|l|}{ SPC } & \multicolumn{2}{|l|}{ (referent) } & \\
\hline \multicolumn{2}{|l|}{ Constraint } & \multicolumn{2}{|l|}{$1.02(0.18)^{*}$} & \\
\hline \multicolumn{2}{|l|}{ Alpha } & \multicolumn{2}{|l|}{$2.86(0.64)$} & \\
\hline \multicolumn{2}{|c|}{ Zero-inflated: days used ETOH at baseline } & \multicolumn{2}{|l|}{$-1.86(3.56)$} & \\
\hline Zero-inflated: constraint ( & -I intercept) & $-0.35(0.61)$ & & \\
\hline LS Means (SE) & & $\mathrm{SPC}$ & ImPAT & $\begin{array}{l}\text { Effect } \\
\text { size }\end{array}$ \\
\hline $\begin{array}{l}\text { Estimate, using global bas } \\
\text { means }^{\mathrm{a}}\end{array}$ & line group & $4.04(0.72)$ & $2.05(0.53)^{*}$ & 0.59 \\
\hline $95 \% \mathrm{CI}, \beta$ (treatment) & & $-1.34,-0.20$ & & \\
\hline Secondary outcome: frequ & ncy of drug use & $\beta(\mathrm{SE})$ & & AIC \\
\hline$(f / u)$ & & & & \\
\hline Days used drugs at baselin & & $0.003(0.02)$ & & 937.2 \\
\hline ImPAT & & $0.022(0.14)$ & & \\
\hline $\mathrm{SPC}$ & & (referent) & & \\
\hline Constraint & & $1.93(0.28)^{*}$ & & \\
\hline Alpha & & $3.06(0.54)$ & & \\
\hline Zero-inflated: days used d & Igs at baseline & $-1.13(0.40)^{*}$ & & \\
\hline Zero-inflated: constraint & -I intercept) & $1.42(0.23)^{*}$ & & \\
\hline LS Means (SE) & & SPC & ImPAT & $\begin{array}{l}\text { Effect } \\
\text { size }\end{array}$ \\
\hline $\begin{array}{l}\text { Estimate, relative to globa } \\
\text { means }^{\mathrm{a}}\end{array}$ & baseline group & $6.85(1.68)$ & $6.82(2.32)$ & 1.01 \\
\hline $95 \% \mathrm{CI}, \beta$ (treatment) & & $-0.25,0.30$ & & \\
\hline $\begin{array}{l}* P<0.05 .{ }^{\text {a }} \text { Marginal means estimated wit } \\
\text { at group means of } 3.97 \text { (ImPAT) and } 4.67 \\
\text { of the primary outcome was also conduct } \\
\text { indicate that the inferences about effect } \\
\text { significant) compared to the primary anal } \\
\text { imbalances in prognostic characteristics v } \\
\text { all of the demographic characteristics lis } \\
\text { education) for their potential to influence } \\
\text { the primary analysis (i.e., in the same di } \\
\text { examines time-averaged effects of the } \\
12 \text {-month follow-up, ImPAT group mem } \\
\text { compared to a 5.6\% reduction in the SPC } \\
\text { in pain was significantly different from } \\
\text { different from zero among those in the SP } \\
\text { Numeric Rating Scale- } 1 ; \text { ImPAT = impro } \\
\text { standard error; } \mathrm{CI}=\text { confidence interval }\end{array}$ & $\begin{array}{l}\text { baseline substance use at grc } \\
\text { PC), for drug use. 'In order } \\
\text { with the last value carried } f \\
\text { f condition were essentiall } \\
\text { is. See Supplemental Table } \\
\text { ich might otherwise bias col } \\
\text { d in Table } 1 \text { (age, gender, } 1 \\
\text { e model and including those } \\
\text { ction and statistically signif } \\
\text { ervention over the } 12 \text {-mon } \\
\text { ers reported a } 16.4 \% \text { reduc } \\
\text { roup; although the between- } \\
\text { ro in the ImPAT condition, } \\
\text { condition. See Supplement } \\
\text { ng pain during addiction tre: }\end{array}$ & $\begin{array}{l}\text { oup means of } 5.73 \text { (Im } \\
\text { to evaluate the potenti- } \\
\text { forward for any obser } \\
\text { ly unchanged (i.e., in } \\
\text { A. In order to exami } \\
\text { mparisons, the primar } \\
\text { racial/ethnic group, p. } \\
\text { e with any indication o } \\
\text { ficant). See Suppleme } \\
\text { nth follow-up interval } \\
\text { ction in pain from ba } \\
\text {-group difference was } \\
\text {, while the percent re } \\
\text { tal Table C. AIC = Ak. } \\
\text { eatment; SPC = suppor }\end{array}$ & $\begin{array}{l}\text { mPAT) and } 4.61 \text { (SPC) } \\
\text { tial impact of missing d } \\
\text { rvation with missing d } \\
\text { n the same direction } \\
\text { ine the potential impac } \\
\text { rry analysis was re-run } \\
\text { partner status, employ } \\
\text { of impact. The results } \\
\text { nental Table B. ' The p } \\
\text { al. With analyses limi } \\
\text { aseline to } 12 \text {-months, } \\
\text { s not significant, the p } \\
\text { reduction in pain was } \\
\text { kaike's information cri } \\
\text { rtive psychoeducation }\end{array}$ & $\begin{array}{l}\text { for alcohol, and } \\
\text { data, the analysis } \\
\text { data. The results } \\
\text { and statistically } \\
\text { act of any chance } \\
\text { after evaluating } \\
\text { yment status and } \\
\text { s were similar to } \\
\text { primary analysis } \\
\text { ited to only the } \\
\text { on average, as } \\
\text { orcent reduction } \\
\text { not statistically } \\
\text { iterion; NRS-1 } \\
\text { nal control; SE } \\
\text { Pain Inventory. }\end{array}$ \\
\hline
\end{tabular}



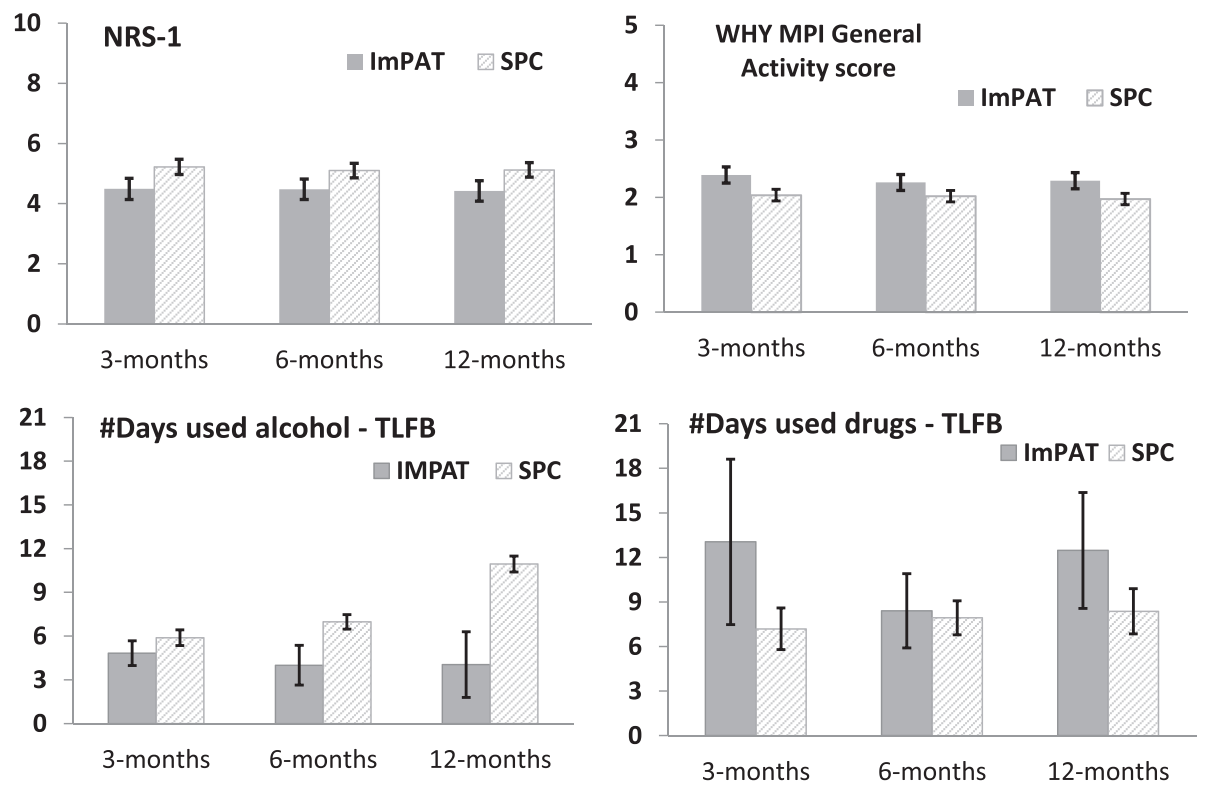

Figure 2 Pain intensity, functioning and time-line follow-back (TLFB) past 30-day assessment of alcohol and drug use, during 12 months of follow-up (all values estimated from adjusted models)

study is the first of which we are aware to provide data supporting the efficacy of a psychotherapeutic pain management approach in adults receiving SUD treatment.

Although the improvements in pain and functioning were statistically significant, the magnitude of the difference was modest. However, it is important to note that this study involved a relatively strong test of the impact of the pain management approach by comparing it to an attention-matched control condition, and overlaying both conditions on top of standard addictions treatment. Prior work indicates that a $15.0 \%$ reduction in pain intensity is an indicator of minimally clinically important improvement [29]. In the present study, although the differences between conditions were somewhat modest, the average reduction in pain intensity ratings from baseline of 1.21 [standard error $(\mathrm{SE})=0.23$ ] for those who received the ImPAT condition approaches what is considered clinically meaningful.

The ImPAT intervention was designed to highlight the relevance of behavioral pain management techniques among individuals with SUDs. The goal was to address pain and the use/misuse of substances simultaneously as a method to cope with pain. Significant differences were found between the intervention and control conditions on days of alcohol use. The results indicate that individuals in both conditions showed initial reductions in days of alcohol use but this remained low in the intervention condition, whereas it generally increased during the 12-month follow-up period in the psychoeducational control condition. No differences were found between the intervention and control conditions on days of drug use during the follow-up interval. Substantial variability was seen in reporting of days of different drugs of abuse at baseline, and the measurement of days of drug use probably lacks precision, consistent with the wide standard deviations around measures of drug use in both the intervention and control conditions. The relatively small sample size of this trial did not allow for the examination of specific drug-related changes in each class of substances. Opioid use disorders, in particular, may be important to examine separately because previous research has found that opioid agonist treatment is important to achieve positive treatment outcomes for those with opioid dependence [30]. Others have developed and are in the process of evaluating interventions unique to those receiving pharmacological treatments for opioid dependence [16]. Larger trials could clarify whether effects are seen on specific substances, and/or whether other substance-specific treatment options could lead to improved effects.

The present study attempted to gather data and analyze data on differences in pain tolerance (as measured by the cold pressor tasks) between conditions. No differences were seen between conditions on this measure. However, many participants refused to complete the cold pressor task, leading to substantial missing data on this measure. In addition, the distribution of the responses further complicated analyses with the existing data. Future work is needed to examine other potential objective measures of pain tolerance as outcomes.

Additional limitations of this study are worth noting. The sample consisted of VA patients and was predominantly male, and the findings might not generalize to other settings. The study also allowed for concurrent treatment of pain within standard care, and the extent to which this might have impacted the results is unknown. Approximately $22 \%$ never attended either the ImPAT or SPC group, due perhaps to the frequent delay between recruitment to 
the start of the groups, and this probably diminished the ability to detect differences between groups. Variability in pain care delivered in addition to the study is not known and not modeled within the present analyses. Although follow-up rates at each assessment exceeded $84 \%$, and $95.3 \%$ of participants had usable data on the primary outcome for at least one follow-up, there is the still the possibility that the reasons for missing data were related to response to treatment condition. This may have biased the results. Also, the study was delivered within a single SUD treatment program with an existing theoretical approach that is supportive of CBT. It is unknown if this potentiated the effects of the intervention or whether this might have made it more difficult to detect effects above and beyond the impact of standard care.

Even with these limitations, this is the first study of which we are aware to demonstrate the efficacy of a psychotherapeutic pain management approach in adults with SUDs. The results provide consistent support for the positive effects of the intervention on pain-related outcomes as well as reduced alcohol use; no significant differences were found between intervention and control conditions on drug use. These findings highlight the potential benefits of this approach for SUD treatment settings and raise the possibility that integrated behavioral pain and SUD services could be particularly beneficial for the large number of individuals with co-occurring pain and SUDs.

\section{Declaration of interests}

None.

\section{Acknowledgements}

This work was supported by the VHA's Health Services Research and Development Service (HSR\&D; IAC 09-047 and CDA-09-204). The views expressed in this report are those of the authors, and do not necessarily represent those of the VHA. We appreciate the support of the patients and staff at the Ann Arbor VA Medical Center substance use disorder treatment program. This study would not have been possible without the work of Felicia Kleinberg, Linda Webster, Betty Bigger and Liz Haas.

\section{References}

1. Ilgen M., Perron B., Czyz E., McCammon R., Trafton J. The timing of onset of pain and substance use disorders. Am J Addict 2010; 19: 409-15.

2. Kennedy J., Roll J. M., Schraudner T., Murphy S., McPherson S. Prevalence of persistent pain in the U.S. adult population: new data from the 2010 National Health Interview Survey. J Pain 2014; 15: 979-84.

3. Von Korff M., Crane P., Lane M., Miglioretti D. L., Simon G., Saunders K., et al. Chronic spinal pain and physical-mental comorbidity in the United States: results from the national comorbidity survey replication. Pain 2005; 113: 331-9.
4. Morasco B. J., Gritzner S., Lewis L., Oldham R., Turk D. C., Dobscha S. K. Systematic review of prevalence, correlates, and treatment outcomes for chronic non-cancer pain in patients with comorbid substance use disorder. Pain 2011; 152: 488-97.

5. Potter J. S., Prather K., Weiss R. D. Physical pain and associated clinical characteristics in treatment-seeking patients in four substance use disorder treatment modalities. Am J Addict 2008; 17: 121-5.

6. Jakubczyk A., Ilgen M. A., Bohnert A., Kopera M., Krasowska A., Klimkiewicz A. et al. Physical pain in alcohol dependent patients entering treatment in Poland-prevalence and correlates. J Stud Alcohol Drugs in press.

7. Trafton J. A., Oliva E. M., Horst D. A., Minkel J. D., Humphreys K. Treatment needs associated with pain in substance use disorder patients: Implications for concurrent treatment. Drug Alcohol Depend 2004; 73: 23-31.

8. Rosenblum A., Joseph H., Fong C., Kipnis S., Cleland C., Portenoy R. K. Prevalence and characteristics of chronic pain among chemically dependent patients in methadone maintenance and residential treatment facilities. JAMA 2003; 289: 2370-8.

9. Caldeiro R. M., Malte C. A., Calsyn D. A., Baer J. S., Nichol P., Kivlahan D. R., et al. The association of persistent pain with out-patient addiction treatment outcomes and service utilization. Addiction 2008; 103: 1996-2005.

10. Samet J. H., Walley A. Y. Can one be an expert in addiction medicine without expertise in pain management? Addiction 2008; 103: 2006-7.

11. McCracken L. M., Turk D. C. Behavioral and cognitivebehavioral treatment for chronic pain. Spine 2002; 27: 2564-73.

12. Morley S., Eccleston C., Williams A. Systematic review and meta-analysis of randomized controlled trials of cognitive behaviour therapy and behaviour therapy for chronic pain in adults, excluding headache. Pain 1999; 80: 1.

13. Chou R., Fanciullo G., Fine P., Adler J., Ballantyne J., Davies P., et al. Clinical guidelines for the use of chronic opioid therapy in chronic noncancer pain. J Pain 2009; 10: 113-30.

14. Hann K. E. J., McCracken L. M. A systematic review of randomized controlled trials of acceptance and commitment therapy for adults with chronic pain: outcome domains, design quality, and efficacy. J Contextual Behav Sci 2014; 3: 217-27.

15. Currie S., Hodgins D. C., Crabtree A., Jacobi J., Armstrong S. Outcome from integrated pain management treatment for recovering substance abusers. J Pain 2003; 4: 91-100.

16. Barry D., Savant J., Beitel M., Cutter C., Schottenfeld R., Kerns R., et al. The feasibility and acceptability of groups for pain management in methadone maintenance treatment. J Addict Med 2014; 8: 338-44.

17. Ilgen M. A., Haas E., Czyz E., Webster L., Sorrell J., Chermack S. Treating chronic pain in individuals with alcohol or drug use disorders. Cogn Behav Pract 2011; 18: 149-60.

18. Farrar J. T., Young J. P., LaMoreaux L., Werth J. L., Poole R. M. Clinical importance of changes in chronic pain intensity measured on an 11-point numerical pain rating scale. Pain 2001; 94: $149-58$.

19. Folstein M. F., Folstein S. E., McHugh P. R. Mini-Mental State: a practical method for grading the state of patients for the clinician. J Psychiatr Res 1975; 12: 189-98.

20. Derogatis L. R. Brief Symptoms Inventory: Administration, Scoring, and Procedures Manual, 3rd edn. Minneapolis, MN: National Computer Systems; 1993. 
21. Kerns R. D., Turk D. C., Rudy T. E. The West Haven-Yale Multidimensional Pain Inventory (WHYMPI). Pain 1985; 23: 345-56.

22. Shumate M., Worthington E. L. Effectiveness of components of self-verbalization training for control of cold pressor pain. J Psychosom Res 1987; 31: 301-10.

23. Willoughby S. G., Hailey B. J., Mulkana S., Rowe J. The effect of laboratory-induced depressed mood state on responses to pain. Behav Med 2002; 28: 23.

24. Sobell L. C., Sobell M. B., Connors G. J., Agrawal S. Assessing drinking outcomes in alcohol treatment efficacy studies: selecting a yardstick of success. Alcohol Clin Exp Res 2003; 27: 1661-6.

25. Sobell M. B., Sobell L. C., Klajner F., Pavan D., Basian E. The reliability of a timeline method for assessing normal drinker college students' recent drinking history: utility for alcohol research. Addict Behav 1986; 11: 149-61.

26. Fey S. G., Fordyce W. E. Behavioral rehabilitation of the chronic pain patient. Аnnu Rev Rehabil 1983; 3: 32-63.

27. Turner J. A., Mancl L., Aaron L. A. Short- and long-term efficacy of brief cognitive-behavioral therapy for patients with chronic temporomandibular disorder pain: a randomized, controlled trial. Pain 2006; 121: 181-94.

28. Fals-Stewart W., Klostermann K. Psychoeducational Attention Control Treament for Alcoholism (PACT): A Guide. Buffalo, NY: The Addiction and Family Research Group; 2004.
29. Salaffi F., Stancati A., Silvestri C. A., Ciapetti A., Grassi W. Minimal clinically important changes in chronic musculoskeletal pain intensity measured on a numerical rating scale. Eur J Pain 2004; 8: 283-91.

30. Weiss R. D., Potter J., Fiellin D. A., Byrne M., Connery H. S., Dickinson W., et al. Adjunctive counseling during brief and extended buprenorphine-naloxone treatment for prescription opioid dependence: A 2-phase randomized controlled trial. Arch Gen Psychiatry 2011; 68: 1238-46.

\section{Supporting information}

Additional supporting information may be found in the online version of this article at the publisher's web-site:

Table S1 Pain intensity across the follow-up period, according to treatment group, with adjustment for baseline pain, missing data imputed via last value carried forward.

Table S2 Pain intensity across the follow-up period, according to treatment group, with adjustment for baseline pain and covariates.

Table S3 Percent change in pain intensity, comparing 12 months follow-up with baseline, according to treatment group. 